\begin{abstract}
"Mircea cel Batran" Naval Academy Scientific Bulletin, Volume XX - 2017 - Issue 2
The journal is indexed in: PROQUEST / DOAJ / Crossref / EBSCOhost/ INDEX COPERNICUS/ OAJI / DRJI I JOURNAL INDEX / I2OR / SCIENCE LIBRARY INDEX / Google Scholar / Academic Keys / ROAD Open Access I Academic Resources / Scientific Indexing Services / SCIPIOI JIFACTOR
\end{abstract}

\title{
EARLY IDENTIFICATION OF CHILDREN WITH SPECIAL EDUCATIONAL NEEDS
}

\author{
Julia DONCHEVA ${ }^{1}$ \\ ${ }^{1}$ Assoc. prof. PhD Faculty of Natural Sciences and Education, Department of Pedagogy, Psychology and \\ History, "Angel Kanchev" University of Ruse, Bulgaria, E-mail: jdoncheva@uni-ruse.bg
}

\begin{abstract}
Early identification of children with special needs is very important activity through which can be realized prevent them or to ascertain at the outset negatives that can more easily be repaired than when the problem is already unmanageable. Before proceeding to use one or the other winning strategy, we must surely recognize children with special educational needs. These deficits needs can be in training or behavior. When it is suspected that a child has special educational problems, check its average intelligence decreases in psychological processes involved in learning; discrepancy between ability and achievement; achievements attained through effort or systematically support. In terms of childhood and kindergarten this can be done through observations from teachers about the presence or not of indicators analyzed in the publication.
\end{abstract}

Key words: early identification, children with special needs, indicators, analyze, childhood.

Even back in 1988 the French government and the French Ministry of Education declared its main goal in pre-school public education early detection of children with learning problems and education and providing special care for them. Today - 20 years later when Bulgaria is already a full member of the European Union, our country is still not paying adequate attention to these children. Moreover - no statistics, no one knows how exactly are these children, what are their problems and how it might help them before they entered the school. Parents of such children are left to wander alone to enter forums on the Internet and each other informed, often incorrectly and competently. Imagine what doom "different" children? On retardation, dismissive of neglect and whatnot - only in negative terms. Children are left to their own luck, and teachers - their intuition and good will to help such cases.

In this regard we need to clarify specifics. Who are the children with special learning and educational needs, which is specific to them and how could it help them? Firstly I would like to emphasize that the distinction between two groups of children with problems, children with special educational needs and children with special educational needs.

needs

Children with special educational

The first group of children talking about some breaches and problems in their training, ie in perception and understanding of new knowledge, learning and intellectual development. Without being outside the norm, they have some problems that prevent them include adequate training and achieve relevant results. Typical of children with special educational needs is that they are not well developed some cognitive functions - memory, attention, speed of processing new information, language processing, perceptual-motor processing, executive functions such as planning and inspection. Affected are important skills such as oral use of language (perception, comprehension, pronunciation) Alalia; reading (decoding and awareness), writing (dictation, graphical expression), mathematical knowledge - dyslexia. Violations in the process of learning are associated with certain organizational capabilities and presence or absence of skills for social interactions (contacts).

According to modern definition of dyslexia is a specific disorder that manifests itself in recurring errors in reading, writing, working with numbers and figures, problems with short-term memory, praxis, and visual abilities. It can also be disturbed the sense of direction and time [Velichkova and team]. Many of these children perform tasks assigned by the teacher slower and require mandatory additional support. Due to violations of verbal communication many of them cannot be actively involved either in the process of adopting a school assignment, nor to explain the outcome.

Dyslexia is not only to problems related to learning and mastering the general teaching skills. Like its peers, children with dyslexia are experiencing the impact of social environment and are forced to comply with rules and requirements it. In no less social environment and attitudes of others influence their social competence. It is customary to assume that children with dyslexia is characterized by a lack of tact and delicacy. Furthermore, they find difficult to understand and adapt to the emotions of others. For this reason can demonstrate inappropriate behavior or insensitivity and detachment. These behavioral characteristics hinder not only the group / class, but also of the child. Other children isolate them 


\section{"Mircea cel Batran" Naval Academy Scientific Bulletin, Volume XX - 2017 - Issue 2 \\ The journal is indexed in: PROQUEST / DOAJ / Crossref / EBSCOhost/ INDEX COPERNICUS/ OAJI / DRJI I JOURNAL INDEX / I2OR / SCIENCE LIBRARY INDEX / Google Scholar / Academic Keys / ROAD Open Access I Academic Resources / Scientific Indexing Services / SCIPIO/ JIFACTOR}

and refuse to communicate with them. The deficit of social skills is concentrated in three main areas: - Lack of appreciation for the moods and attitudes of others;

- Difficulties in adapting to the atmosphere in a particular social situation;

behavior.

$$
\text { Demonstration of unacceptable }
$$

Children with specific disorders learning ability can hardly meet the expectations of others especially in terms of learning and mastering skills and school behavior. For this reason they are experiencing failures more often than other children. Recurring failure formed in the child negativity and distrust for the other.

In the last year or two it has become obsolete to talk about the integration of children with developmental problems and learning in mainstream school. Integration and education of these children should start from pre-school age. Unfortunately, the fact is that in Bulgaria there are still children with mild mental retardation or any of those specifics are not trained, who are left only in the hands of his family. Often such children put stigma "is not subject to education" and in fact they fall into the group of pedagogical neglected children. Especially if the parents are not educated or do not have the financial ability to hire specialists for your child.

The functioning of the family is also affected. Much of dyslexic children showed some emotional discomfort in the presence of a brother or sister who have no such violations. This discomfort due to the rivalry, it is possible to reach a manifestation of hostility or aggression even to a brother or sister. Commonly seen regress in behavior aimed at parents as "revenge for neglect."

Children with dyslexia do not shine with particular success, but just diagnosed clarify their problem and the development of adequate training strategy could get ahead in their cognitive development. Sensitive period for assistance and perform corrective work on children with dyslexia is between the third and fourth year, i.e. preschoolers. When these children are not recognized by the health and education systems, they can not rely that they will receive adequate to their needs care and attention. Moreover - they are doomed to remain isolated in one corner of the daycare (if accidentally accepted them in kindergarten) and more to sink into the darkness of their destiny.

This summer under the specifics of my professional interests are faced eight year old boy with mild mental retardation (diagnosis by competent health institutions). So far it does not communicate verbally with adults, presence of children not excited, not interested in the colorful diversity of the world around him. Child was abandoned, on the contrary, it is well watched and cared for a child, but only with regard to his health, food and clothing. As for his mental and cognitive development, to the expression of his emotions - he responded to two-three year old. Parents throughout its existence - from two to eight years his age are asked ourselves what to do with it. And not received a response. In kindergarten they accepted it but told them that it sits in the corner and did not wish to take part in any games other children or in organized forms of training. Similar responses or observations received and dozens of other children. And this happened not because of lack of willingness to find a way out of the problem. It has happened due to lack of training of teachers to work with such children. It was possible due to the lack of requirements for healthcare institutions not only to diagnose these children, but also to offer options out of this diagnosis. Or at least partially overcome it. Otherwise, these children fall under the heading - "pedagogical neglected child." Parents of these children did not show parental negligence. They do not know where, how, what, and do not have to know everything about light mental retardation, autism, dyslexia, a hyperactivity of childhood aggression Alalia to dizartikulatsya etc. However, this is a specialized area of human knowledge and work of specialists - teachers, psychologists, and psychiatrists.

We are well aware that dyslexia and Alalia can not be cured completely, but with timely and adequate professional measures can be avoided possible negative consequences of them. In this case it is particularly important early intervention and the creation of individual training programs for such children. In addition, parents should be informed in time and know that their children can be educated that are possible good results that will occur after more and longer during efforts.

Alalia is another kind of deviation from the norm, which means no or no further development of speech arising as a result of organic lesions of the central nervous system. The reasons for Alalia are mostly generic injuries and diseases of the brain in children up to 1.5 years of age, leading to deterioration of speech in areas of the cerebral cortex. Depending on what speech centers were overwhelmed distinguished "motor Alalia" - not a development of speech partially preserved understand foreign speech and "sensory Alalia" violated the understanding of speech. It is also combined disorder - "Cinsaut-motor Alalia". In Alalia violated all components of speech Phonetics-phonematic country and lexical and grammatical. When the sensor Alalia child hears that person says something, but does not 


\section{"Mircea cel Batran" Naval Academy Scientific Bulletin, Volume XX - 2017 - Issue 2 \\ The journal is indexed in: PROQUEST / DOAJ / Crossref / EBSCOhost/ INDEX COPERNICUS/ OAJI / DRJI I JOURNAL INDEX / I2OR / SCIENCE LIBRARY INDEX / Google Scholar / Academic Keys / ROAD Open Access I Academic Resources / Scientific Indexing Services / SCIPIO/ JIFACTOR}

understand what is, and when the motor Alalia the child can not master Speech - sounds, words, grammar. New words in speech these kids are slow to appear, and those who use are directly related to lifestyle. They do not use prepositions, particles, adjectives. The use of all grammatical forms of children Alalia is difficult. It manifests Agrammatism expressed as: number;

$$
\text { - lack of consistency in gender and }
$$

-lack and incorrect use of pronouns;

-violations sequence of words in sentences;

- lack or limited use of simple and complex sentences extended.

From made explanations about the nature of Alalia it is clear that a child with such a diagnosis will be hampered in his training group/ class. This is why it is essential to care for an individual program, which is made in advance by a child psychologist, speech therapist and teacher of the group. Since at this stage in kindergartens will psychologist and speech therapist, any assurances that the child works individually in vain and do not correspond to the actual situation.

Another violation of proper audio pronunciation is meant by the term dizartikulya. It can occur in the release, return or incorrect pronunciation of sounds. May be affected a sound - such as "P" or similar in articulation characteristics - "C", "S", "C", which is known in the literature as monomorphic dizartikuliya, or some sound from different groups - polymorphic dizartikuliya. The reasons may be organic or functional. Organic - defects of the teeth, bite, tongue, lips, soft palate, making it impossible precise enunciation of the respective sounds. Functional reasons expressed in improper functioning of the various departments of the central nervous system responsible for the correct perception of phonemes or their precise articulation. As for the first group of reasons removing them entirely in the hands of parents and their good will. Functional causes are not removable and suggest specific care by appropriate specialists. Improperly digested pattern or copying defective utterance in the early period may continue until school age, sometimes very persistent and cause violations of reading and writing. The correction of this problem be carried out by specialists - speech therapists on a particular system. Timely and targeted intervention in preschool ensure the utilization of proper pronunciation, better development of phonemics hearing and readiness for literacy in first grade.

Children with special educational needs In the second group it comes to children who have difficulties of emotional and social difficulties.
These are called dis adaptation children and children who have abnormalities in emotional, intellectual, moral and social development, making it difficult to integrate in the children's group or class in the school community.

Which children call not adapted? Children who have difficulties in adapting their respective social environment or situation. They are unable to perform normal social role (child in the group, student, child in the family) to meet their own requirements and needs of society. Depending on the situation of developing adaptation is not: family, school, social and professional.

The reasons for not adaptability can be of various kinds: physical (motor abnormalities), sensory (blindness, deafness), intellectual (weak, insufficient intellectual skills) characterological (character traits - passivity, hyperactivity, aggression), emotional (frustrated, depressed, and abused).

Children who have physical, sensory and mental disabilities belong to the group of children with special educational needs and therefore will not be subject to this article.

All other children with problems of integration into the environment are the subject of special attention of social pedagogy and psychology, i.e. not only children's teachers, but also social workers and educators. The last two groups of professionals are not present in the statutory staff of kindergartens. Moreover, there is no speech therapist and a pediatrician. And we all know how important the further personal development and upbringing of the child are those first seven years. So there will be children who continue to call "difficult" and often refuse to do.

Emotionally not adapted are most often those children who are oppressed social and emotional needs, they were often subjected to violence - physical and mental, and did not receive the necessary love, care and affection. Since the suppression of the social needs of the child (frustration) formed therein inability to orient itself independently in the laws and norms of society (the group or class) rules and norms for relations between people, it makes you feel different and isolated from others. This isolation pushes children to negative actions. This forms a group of children with abnormalities in emotional and social development.

Another group of children, who also can not cope with the requirements of the social environment and in particular the group in kindergarten are children with limited abilities. All they need special care and attention from both the teacher and the school psychologist or guidance counselor. Not adapted children should not be subjected to punishment and ridicule, and to 


\section{"Mircea cel Batran" Naval Academy Scientific Bulletin, Volume XX - 2017 - Issue 2 \\ The journal is indexed in: PROQUEST / DOAJ / Crossref / EBSCOhost/ INDEX COPERNICUS/ OAJI / DRJI I JOURNAL INDEX / I2OR / SCIENCE LIBRARY INDEX / Google Scholar / Academic Keys / ROAD Open Access I Academic Resources / Scientific Indexing Services / SCIPIO/ JIFACTOR}

receive timely qualified assistance. The sooner you discover the reasons for their inability to integrate, the more likely it is to avoid negative complications and prevent failure in school and in life. For this purpose it is necessary to unite efforts of teachers and psychologists (one more reason to have them in every big kindergarten). Their work is the following: detection of problems and determine an action plan for each child separately. Coordinating efforts continuity in the activities uniformity requirements. [Vitanova] There are at least five types of behavior of children who do not fit the conventional model of good behavior. This prevents their successful training, socialization and hinders their integration into infant group and class. These effects in turn lead to a de facto expropriation of children from kindergarten and school. These five types of different behavior separated groups of aggressive, passive, worrisome, hyperactive and gifted children. All they are part of the conduct that facilitates learning and communication. Because of this attention to these children should be special, but in any case - negative or dismissive. This is because the "behavioral patterns, congenital in man, are infinitely flexible and susceptible of modification" [Smirnova, p. 69]. We will focus on each of these five groups to clarify their specific characteristics and seek any appropriate strategies for dealing with them. Of all five types of behavioral problems most attention from researchers is paid to aggressive children, because the consequences of their behavior occur most long - often for life. Furthermore, they have a particular importance for the development of society.

In the US, in Denver and Nashville [Nikolova, Smirnova, Strain, Phillip S.; Timm, Mathew A., 2001] has developed a program for long intervention and training parents to create skills for working with preschool children who have various forms of behavioral abnormalities aggression and antisocial behavior. According to the authors of the program $\mathrm{Ph}$. Strain and $\mathrm{M}$. Timm children with emotional or behavioral disorders form a population of young people who are provocative, rebellious, stubborn and creating a lot of trouble. They come to the attention of various social and preventive care. The authors comment that behavioral problems are subject to adjustment and development as early as preschool and are justified as follows:

- Early appeared behavioral problems in preschoolers are the most accurate harbinger of delinkventnost into adulthood, leaving the community and jailed.

- The stabilization of aggression around the age of ten is equivalent to building and stabilizing the intelligence at this age. In other words, as the intelligence acquired in childhood remains available to the individual for life and acquired, developed and established aggressiveness remains available to the individual.

- If the aggression to others not to finish in '13, it may become a chronic behavior.

A child growing among adult perpetrators, are more likely to leave school early, fall into custody to be drug and alcohol dependent, to marginalize or die early.

Timely intervention aimed at developing relations parents - a child is the most effective strategy for rejection of early behavioral problems. In the process of socialization aggression permanently reduced if the child is learning to regulate their emotions and to resolve conflicts without aggression activates [Bugin, Hotton, Rivara, Strain]. Such a statement gives us reason to think that even possible human aggression have instinctive component, it could lend itself to modification. Preschool children, who have not forgotten aggression in the family during this sensitive period of development, are at risk of serious behavioral problems in childhood and early adolescence. The problems of aggressive behavior that emerge and stabilize during the preschool years - a period of dramatic cognitive, linguistic and emotional development - are important for antisocial behavior (violence, crime, and early school leaving and drug addiction) in adolescence and adulthood. In fact aggression is the clearest harbinger of criminal behavior before '13 and a risk factor for drug use [Bugin, Ilieva]. From this perspective wild, unbridled aggression early leads to accumulation or accumulation of additional risk factors (social and emerging). The trajectory of antisocial behavior leads to serious problems of criminal behavior, which is more difficult and costly to resolve and overcome. For the young child, which is characterized by constant aggression and disobedience (delinquency behavior), and others with whom the child is in contact (family, educators, peers), the price includes: early and constant rejection from their peers; mostly criminal contacts with teachers; family relationships that are unpleasant for all; predict school failure and possibly early school leaving [Strain, Budin, Hotton]. Usually the public perceives these children as torturers others as destroyers of public rules. The price of unbridled aggression paid by society is this: millions paid for the arrest of young aggressors; millions smashed paid for their property; millions paid for adult prisoners who have shown more aggression in preschool [Strain, Dineva]. In fact, they are the most dangerous to themselves because their behavior provoke a high risk of fatal accidents, 


\section{"Mircea cel Batran" Naval Academy Scientific Bulletin, Volume XX - 2017 - Issue 2 The journal is indexed in: PROQUEST / DOAJ / Crossref / EBSCOhost/ INDEX COPERNICUS/ OAJI / DRJI I JOURNAL INDEX / I2OR / SCIENCE LIBRARY INDEX / Google Scholar / Academic Keys / ROAD Open Access I Academic Resources / Scientific Indexing Services / SCIPIO/ JIFACTOR}

pass to alcoholism, use of drugs, remain unemployed as adults, have the most divorces are endangered by mental illness throughout life or of early death [Klimentová, Doncheva (2014)]. It is well known from theory and practice that the behavior of children of occupation or in class depends largely on the success of teaching and the personal successes of each of them. On the other hand, the behavior is not entirely genetically determined and in the power of adults to help it to correct. The activity of the individual in carrying out an activity depends on the degree of motivation of personal qualities and the level of development of cognitive and motor activity of the student. Only when this set of conditions is met can expect successful school activities and results. Usually in kindergarten and elementary school pays most attention to the development of cognitive and gross motor activity. Personal qualities and in particular the behavior of the child/student most difficult to control and therefore avoided by teachers or act in the wrong direction.

We must pay attention to another category of children - passive and embarrassing. They are difficult to express difficult establish contacts and therefore are often isolated and lonely. A good teacher involves them in solving interesting and accessible to their capabilities tasks puts their responsibilities, creates conditions to be responsible for the results of collective activities and games. Highlights their successes and encourage them. Avoid situations that would make them worried and depressed. In other cases, these children experience constant frustration from the inability to express or the fact that they are not noticed. Very often we have seen a "sudden" outbreak of militancy or infringe on his own personality (selfaggression) of such children. And always with astonishment and regret teachers reported that it (the child) was quiet, modest and inconspicuous. In fact, there is nothing surprising. The constant neglect, suppression of desires (whether it is caused by inner modesty and shyness) taunts of other children in the group or class does not lead to anything except to frustration. And then to aggression only one step.

A large group of children who have trouble adapting to kindergarten and school are hyperactive children. Because of their impulsivity and high physical activity hyperactive children are inattentive, it is difficult to focus on the task and not always achieve the desired result. This puts them in a different position in the group and in the class - more often as failed and losers, rather than succeed. This situation is repeated often and is the reason for the backlog of children in mastering the educational content. What is $A D H D$ ? Increased activity, coupled with an inability to concentrate, impulsivity, constant agitation and lack of control. For all these events hyperactive child cannot cope with their duties perceive new knowledge and gradually lagging behind its peers. Manifestations of ADHD are:

- The inability of the child to keep in one place during the learning process - occupation or lesson;

- Restless, frequent movements of the limbs or the entire body;

- Inability to safely and accurately completing assigned tasks during training or game;

- Continuing need for movement unless it is necessary for the situation;

- Continuous striving to be the center of attention of parents, teachers or peers. In many cases resorting to negative and aggressive behavior.

Hyperactive child has the impulsiveness of behavior and character, which is expressed in his desire to answer a question without being heard fully. For this reason, it does not give the correct answer, which leads to frustration and makes it irritable. When such cases are repeated often, the child falls into this frustration and to some extent the reason for the negative behavior. Moreover - this leads to acts of aggression directed towards others (external aggression) and itself (self-aggression). During the game hyperactive child cannot wait his turn, does not comply with the rules and this is often the cause of conflicts. Inability to focus to details such child makes a lot of mistakes and led the decision of the task completely. It is unable to listen carefully caller, your partner or teacher and does not perform the task. Shows reluctance in performing tasks that require sustained mental effort. So often we hear from these children "do not want", "will not do", "I do not like." In such cases, adults are more inclined to interpret such behavior as an expression of stubbornness or obstinacy and this often causes them to adjust negatively against the child. When working in a group, the behavior of hyperactive child is a reason for the failure or delay in fulfillment of the given common task. Other children disapprove of such conduct and seek to isolate, not prevent them. This leads to irritation and even greater aggressiveness. In this way a closed vicious circle in which, if guilty, it is not the child. It is necessary to use special tests for such children and then administration of drugs or techniques and teaching methods to reduce their hyperactivity, which made the child selfcontrol behavior (verbal and non-verbal support from teacher to correct behavior, discussing with your child/student of negative fragments of his behavior, creating a class of conditions that do not distract the child from performing the tasks, etc.). 


\section{"Mircea cel Batran" Naval Academy Scientific Bulletin, Volume XX - 2017 - Issue 2 \\ The journal is indexed in: PROQUEST / DOAJ / Crossref / EBSCOhost/ INDEX COPERNICUS/ OAJI / DRJI I JOURNAL INDEX / I2OR / SCIENCE LIBRARY INDEX / Google Scholar / Academic Keys / ROAD Open Access I Academic Resources / Scientific Indexing Services / SCIPIO/ JIFACTOR}

Gifted children are also considered at risk of isolation and misunderstanding of teachers and children in the children's group or class. Because of its diversity and considering the development of specific talents, they are difficult to adapt to the general requirements and rules. Traditional knowledge age and educational content did not satisfy them and make them interested. When teachers do not take into account that their difference and do not prepare them for individual tasks (due to unwillingness to impede or ignorance how to do it), these children bored hinder others and himself a teacher. Not rare cases when teachers punish them, instead of trying to understand the reasons for their behavior. So instead develop their special talents, they are threatened by the risk to drop out of the group or class. This is the gloomiest outlook for these children.

Working with the homeless and street children. The phenomenon of street children is one consequence of the economically unfavorable conditions in our country. In recent years this phenomenon has expanded its range both in social and in the age aspect. Increasingly age limit of homeless and street children coming down the street remained 6-8-year-olds. It also varies and their ethnic composition - not only Roma, but increasingly there are children of ethnic Bulgarians. Others on the street, these children cannot attend kindergarten or school. If that happens, they feel relaxed and equal to others. This is because the homeless and runaways from their families come from an environment of instability, early deprivation (deprivation) and abuse. As a result - many children do not trust any authority and be wary of institutions (school). They acquire destructive (destructive defeatist) behavior. Sabotage everything, even their own success and their first encounters with adults are typically hostile. These peculiarities of behavior must be taken into account by teachers and such behavior cannot be answered with penalties and prosecution or declaration of war. In this case it is best to proceed to clarifying the rules of the institution (kindergarten or school), the position of the child in the group or in class, the expectations for him. Moreover, they should show convincingly goodwill of teachers and children and on this basis to build a relationship of trust and cooperation.

"Problem children". It is known that children at risk and those who are worried because of their differences, cannot concentrate on everyday material in the traditional classroom. Because they have not lived for a while in a normal family environment and did not attend school, they miss teaching material and relevant knowledge. Circumstances and teachers pressuring them to catch not only the material but also social skills. This additional stress and burden them and anyone even the slightest failure can cause them again to return to the street. If they fail to meet these requirements, they gradually fall behind and fall into the group of "problem children". Many of them lack the heart and they also find it difficult. As a result, very intelligent and clever children are in classes slowly developed. Their self-esteem suffers and many of them are at risk of dropping out (dropping out). When working with homeless and street children should be borne in mind that they have different characteristics, different from that of married children:

- They have a strong concern on the attitude of adults towards them and expression are excited what will be the effect, how they react others. When you feel that adults endeavor to help them, they reward them with good behavior and good results. Revealed confidence of teachers always brings positive results. Teachers often fail success of these children displaying behavior and actions that they think about different or difficult training and education.

- Homeless have the same sensory experience as other children. They do not know how to use the phone or dictionary, for example. So set by the teacher task that provides such a thing bother them. The same is true for the children of poor families when their assignment to find any literature or obtain information. This immediately affect their self-esteem puts them at a disadvantage compared to other people's negativity to the institution. School readiness is a problem for street, homeless and street children.

- Substantial abuse (psychological, physical or sexual) - by parents and young - the norm of respect to abandoned (cast off) and street children. This suppresses them, embittered them and makes them aggressive or deprivation. - In elementary school many homeless realize that they are "different". The other children also realize it and this creates tension in their relations. Irritability and anxiety are a common problem for the whole class and only good pedagogical skill of the teacher can change the situation. Moreover, it is necessary for their training and education to intervene with special programs, school psychologists or pedagogical advisers. Only timely and concrete measures can help homeless and street to overcome their differences and successfully complete their education.

How to recognize children with special educational needs? Before proceeding to use one or the other winning strategy, we must surely recognize children with special educational needs. As we said, these needs can be in training or education. When it is suspected that a child has 


\section{"Mircea cel Batran" Naval Academy Scientific Bulletin, Volume XX - 2017 - Issue 2 \\ The journal is indexed in: PROQUEST / DOAJ / Crossref / EBSCOhost/ INDEX COPERNICUS/ OAJI / DRJI I JOURNAL INDEX / I2OR / SCIENCE LIBRARY INDEX / Google Scholar / Academic Keys / ROAD Open Access I Academic Resources / Scientific Indexing Services / SCIPIO/ JIFACTOR}

special educational problems, check its average intelligence - decreases in psychological processes involved in learning; discrepancy between ability and achievement; achievements attained through effort or systematically support. In terms of kindergarten this can be done through observations by teachers whether or not the following indicators:

Indicators of the presence of a risk of occurrence of difficulties in learning: vocabulary deficits; inadequate knowledge; lack of or poor knowledge of semantic and syntactic structure of the language; inadequate skills in understanding and differentiating enshrined in the text humor idea explanation, dialogue, etc., i.e. content analysis; difficulty in differentiating and determining the number of syllables in the word; problems memorizing and reproducing verbal information; delays or imbalance in development. Perceptual-motor problems associated with attention deficit and hypercinectiks. The motivating factors are not decisive, but their presence can affect success in learning.

Violations and restrictions in oral speech problem articulation and practical skills of preschool children who are most often associated with problems in neuro-physiological development are cause of later problems with reading and limited phonetic awareness elementary school. This leads to retardation of children and requires special attention and individual work. It is important to distinguish between the concepts of learning disorders and developmental disorders. In developmental disorders is necessary to use adequate individual training programs and development of modified type, while specific learning disorders suggest structuring and implementation of tailored individual programs.

Determining levels of current and near development. Of great importance is in kindergarten to determine levels of current and recent development of each child. This can and should be done at the beginning, middle and end of the year. Such activities should be performed by a child psychologist or social pedagogue to ensure professional performance diagnostics. In a special diagnostic card is characterized attention of the child's observation, imagination, thinking, practical skills and habits. This allows the teacher to adjust its relationship with the child during the occupation and free communication. The pedagogical advisor is one that can and should organize meetings of teachers to freely discuss issues related to children and approaches to work and interaction. To organize and consult parents on age and individual peculiarities in the development of their child's readiness for school, for brilliance and his ability to specifics of communication with adults and peers for specifics behavior and their relationships with peers and adults [Voenkinova].

Prospects. Creating regional centers to work with these children would facilitate both parents and teachers. There must be located dossier for every child and accordingly prescriptions for dealing with it. Describe findings on progress or lack of such new recommendations. These centers use different strategies for working with children. As shown, the work is not easy and requires no special training of preschool teachers as they do not actually get under preparation at the university. Despite hundreds of examples of teacher frustration and educational failures with such children, preparing children and elementary school teachers in universities is aimed primarily at working with children the norm. If there somewhere mentions cases outside the norm (for children in abnormal), it is occasionally in the form of several lectures. Well-prepared future teachers could select the most appropriate forms and methods of working with such children.

In conclusion I would say that the institutions are debtors of children with specific learning and educational needs. If we continue to pretend that these children and their problems do not exist, there is a risk the number of young people with antisocial behavior and antisocial acts to increase. Hundreds of children with such problems remain outside the society and actually takes them right to education and development. These children should be seen by all pedagogical and administrative community as children at risk, which should take special care and attention. Only then can we expect their specific needs to be met, and their number becomes smaller.

\section{BIBLIOGRAPHY}

[1] Bugin, Patricia, Voices from the field - Public policies and the prevention of early childhood aggression (online, 05.06.2004).

[2]Dineva, $\mathrm{V}$. The validity of the diagnostic criteria in computer addiction and dysfunctional use of the Internet. Scientific University of Rousse, 2015, Volume 54, Series 6.2.

[3] Doncheva, J. Educational-Pedagogical work interaction with children with oppositional defiant behavior, Scientific Bulletin" Mircea cel Batran" Naval Academy, 2015. 
"Mircea cel Batran" Naval Academy Scientific Bulletin, Volume XX - 2017 - Issue 2

The journal is indexed in: PROQUEST / DOAJ / Crossref / EBSCOhost/ INDEX COPERNICUS/ OAJI / DRJI I JOURNAL INDEX / I2OR / SCIENCE LIBRARY INDEX / Google Scholar / Academic Keys / ROAD Open Access I Academic Resources / Scientific Indexing Services / SCIPIOI JIFACTOR

[4] Doncheva, J., Consolidating functions of Bulgarian children's folk games in preschool, Ruse, 2014.

[5] Dyslexia (Psychology of abnormal development). www.psihologia.net.

[6] Hotton Tina, Childhood aggression and exposure to violence in the home, Canada, 2003.

[7] llieva, I. The motivation for sport at school age, Ruse, 2012.

[8] Klimentová, A, Implementation of brain based learning in teaching at schools, 2012.

In Current Trends in Educational Science and Practice I: International Proceedings of Scientific Studies; -

Nitra: UKF, p. 47-55, 2012.

[9] Nikolova, Sn. Integration and correction of students with mental retardation in Bulgarian schools. In:

Proceedings "Innovation in Education", Shumen. "Bishop Konstantin Preslavki", Faculty of Education, 2010.

[10] Rivara Frederick P., MD.MPH, Youth Violence: Causes and Prevention (on line).

[11] Smirnova, E., V. Holmogorova, Preschool age: the formation of friendly relations. 9/2003, p. 68-74.

[12] Strain Phillip, Timm Matthew, Remediation and Prevention of Aggression: An Evaluation of the

Regional Intervention Program Over a Quarter Century

http://connection.ebscohost.com/c/articles/10189743/remediation-prevention-aggression-evaluation-regionalintervention-program-over-quarter-century.

[13] Velichkova, M., H. Melinios, S. Pencheva. Visual-spatial deficits in developmental dyslexia.

Psychological research, 1/2003, Sofia.

[14]Vitanova, N. Rights and duties of teachers

Bulgarian schools Scientific University of Ruse, 2015, Volume 54, Series 6.2.

[15] Voenkinova, J., Problems of the victimization Scientific University of Ruse, 2014, Volume 53, Series 6.2. 